\title{
Application of adjacent heating technology in thermal power unit
}

\author{
Yongqiang Che ${ }^{1,2, *}$, Yanfei Zhang ${ }^{3}$ and Haizhen Lv ${ }^{4}$ \\ ${ }^{1}$ Shandong Electric Power Research Institute, Jinan, China \\ ${ }^{2}$ State Grid Shandong Electric Power Research Institute, Jinan, China \\ ${ }^{3}$ National Energy Group Shenhua Guohua Shouguang Power Generation Co., Ltd, Shouguang, China \\ ${ }^{4}$ Shandong Zhongshiyitong Group Co., Ltd, Jinan, China
}

\begin{abstract}
There are many problems in the start-up stage of thermal power unit, which seriously affect the safe and economic operation of the unit. Therefore, it is of great significance to study the energy-saving technology of thermal power unit in the start-up stage. The adjacent heating technology is put forward to solve these problems in the boiler start-up stage. Thermal power unit USES the adjacent machine heating technology, improve the conditions of the boiler ignition and steady combustion conditions, improve the safety of the boiler start-up, saves the costs of fuel oil, coal, electricity, strengthened the flushing efficiency, shorten the flush time, improve the economic benefit of the adjacent machine, and prevent the scale caused by dramatic change wall temperature fall off, It can also ensure the safe operation of desulfurization, denitration and dust removal devices, and reduce the emission of pollutants, so it has a broad application prospect.
\end{abstract}

\section{Introduction}

As the goal requirements of "carbon peak, carbon neutralization" and "building a new power system with new energy as the main body" are put forward one after another, the position of thermal power units in the power supply structure is changing from electric power to regulatory power, and the frequency and depth of thermal power units' participation in the peak and frequency regulation of the power grid is increasing day by day. In this new situation, thermal power units should not only meet the demand of peak and frequency modulation of power network, but also ensure the safety and economy of unit operation. However, in the start-up stage of thermal power units, problems such as high energy consumption, stable combustion difference, and excessive emissions have always existed, which seriously affect the safe and economic operation of thermal power units [1]. Therefore, it is of great significance to study the energy-saving technology of thermal power units in the start-up stage. The adjacent heating technology is put forward to solve these problems in the boiler start-up stage.

This paper mainly studies the application of the adjacent heating technology in thermal power units. After fully investigating the situation of the power plant that adopts the adjacent heating technology, the adjacent heating technology is summarized from the aspects of the technical scheme, operation measures, considerations for switching off, economic benefits, safety benefits, environmental benefits and so on. Other types of adjacent heating schemes are also briefly described.

\section{Problems existing in boiler start-up stage}

Once-through boiler of supercritical unit and above for soda quality request is higher, when the boiler is in a state of cold start, the need for boiler body heat exchange surface and tube first, such as water supply pipeline, economizer, water wall, such as water separator for cold washing and hot washing [2-3], the purpose is to remove sediment in the water pipe and heat surface of impurities such as scale, Ensure the surface of boiler heat exchange surface is clean.

In cold flushing, the furnace side should be flushed through the feed water flow rate of about $25 \%$ $30 \% \mathrm{BMCR}$. When the water quality Fe ion concentration at the inlet of the separator or the outlet of the storage tank passes the test, the cold flushing is finished. According to the requirements of the manufacturer, in order to effectively prevent the generation and peeling of steam side oxide skin on the heating surface, it is necessary to control the temperature rise rate of the heating surface wall and the pressure rise rate of steam side pressure. When the temperature of the outlet of the water wall of the boiler or the inlet of the separator rises to $190^{\circ} \mathrm{C}-280^{\circ} \mathrm{C}$, hot flushing shall be started. Until the water quality $\mathrm{Fe}$ ion concentration at the inlet of the separator or the outlet of the storage tank passes the test, the hot flushing is finished. Boiler hot flushing has certain requirements on water temperature, so before boiler hot flushing, it is necessary to start the boiler to heat the water supply.

\footnotetext{
* Corresponding author: cheyongqiang163@SEPRI.com
} 


\subsection{Large energy consumption and stable combustion difference}

Startup boiler in the cold, ignition directly, because the temperature is low, pulverized coal injection into the boiler furnace cannot quickly caught fire, the flames of the risk of fluctuating even flameout in order to ensure the stable combustion, need with lard gun firing or micro oil ignition or plasma ignition combustion mode, it will bring a certain amount of oil, coal, electricity cost, startup boiler efficiency is low, economical efficiency. And the start-up stage of pulverized coal combustion rate is low, fly ash, ash and other combustible content is high, low temperature corrosion and secondary combustion risk exists in the tail flue, seriously affecting the safe operation of boiler tail flue equipment.

\subsection{Overtemperature of superheater and reheater}

The flame in the starting stage of the dc boiler has strong rigidity, and the long and high temperature flame directly scour the convection heat exchange surface. Before the water supply in the water wall is heated from liquid to vapor state, the superheater and reheater are always in the dry burning state, and the tube wall is easy to overtemperature. If there is water in the U-shaped arrangement of the heat exchange tube, the steam flow is small at the start stage, which is not enough to discharge the water, and the heating surface will still be in a local dry burning state. In addition, the oxide scale accumulated at the bottom of the heat exchange tube or the elbow will also make the steam flow in the tube smaller, resulting in poor cooling effect of the tube wall and tube wall overtemperature, which will affect the safe operation of the boiler.

\subsection{Scale generation and shedding}

Before boiler ignition, the tube of superheater and reheater is filled with air with high oxygen concentration. After boiler ignition, the wall temperature of superheater and reheater rises, the tube is in a state of oxygen rich and there is a certain amount of water vapor, and the inner wall is easy to produce oxide skin. At the initial stage of startup, the low temperature wet saturated steam enters the superheater and reheater, which has high convective heat transfer coefficient and strong heat absorption capacity, good cooling effect on the tube wall, and fast wall temperature drop. Due to the different linear expansion coefficient of the tube wall material and the oxide skin on its surface, the oxide skin falls off.

If the peeling oxide skin can not be taken away by steam, but accumulated at the bottom or elbow of the heat exchange tube, it is easy to cause overtemperature and lead to tube explosion. If it is taken away by steam and broken into small particles, it will enter the cylinder in the process of starting and turning of steam turbine, which will easily cause erosion damage to the dynamic and static blades of the flow part of steam turbine, leading to a significant decrease in the efficiency of steam turbine.

\subsection{Emission levels}

SCR inlet flue gas temperature at the start stage generally needs to reach $290^{\circ} \mathrm{C}$ or higher, denitration system can be put into operation, for SCR denitration system, due to the unburned soot or soot adhesion of the boiler, catalyst surface temperature is lower than the wall acid dew point, prone to low temperature condensation, ash blocking, catalyst poisoning and even secondary combustion, etc., Nitrogen oxide emissions in the start-up stage exceeded the standard.

In addition, the risk of low temperature corrosion and secondary combustion caused by high combustible ash and low smoke temperature is also the same. In order to ensure the safety and efficient operation of electrostatic dust removal device, the power plant generally puts into operation electrostatic dust removal device late, which also causes the flue gas dust in the start-up stage to exceed the standard. In the start-up stage, due to poor dust removal effect, flue gas including unburned oil, coal powder and dust enters the desulfurization system, affecting the activity of absorbent, leading to the decrease of desulfurization efficiency, resulting in sulfur dioxide exceeding the standard.

\section{Adjacent heating technology}

In order to solve the above problems in the boiler start-up stage, some power plants in Shandong province have implemented or configured adjacent heating technology. The general idea is to use adjacent steam to replace fuel oil and coal to heat the water supply, the specific approach is to connect the adjacent steam to the high-pressure heater to heat the local water supply, improve the temperature of the local water supply. Heat the water through the economizer of boiler, steam separator, water wall, etc., to the whole preheating of boiler body, when the boiler ignition is in "hot, hot stove, hot environment" the favorable condition, to avoid the partial combustion for pulverized coal furnace caused by low temperature caused by the tail flue of the boiler and air preheater secondary combustion, Greatly improve the boiler ignition conditions and stable combustion conditions, improve the boiler start safety. In addition, in the hot flushing stage, the boiler does not need ignition, thus reducing the consumption of fuel oil or coal at the initial stage of the boiler start-up, and also reducing the power consumption of the boiler's main auxiliary machine, reducing the emission of pollutants.

It is worth noting that the adjacent heating mentioned in this paper is different from the adjacent heating. The latter is mostly used in the subcritical steam drum furnace. The steam source comes from the adjacent steam drum or auxiliary steam system, and is connected to the water wall descending pipe or water wall lower collecting box of the boiler.

In the hot flushing stage of boiler, the boiler feed water is heated to the temperature required by hot flushing as soon as possible through the adjacent heating system, which improves the hot flushing effect and shorts the hot flushing time. In the stage of boiler temperature rise and pressure boost, the temperature of boiler feed water is 
further raised through the adjacent heating system, and the steam production of boiler is increased, so as to shorten the time of boiler temperature rise and pressure boost, so that the main steam pressure can meet the requirements of blanking conditions as soon as possible.

\subsection{Steam access machine high add scheme}

Configuration between the two sets of machine heating system, need to first select extraction steam source, in order to heat the boiler feed water from $80{ }^{\circ} \mathrm{C}$ to $190{ }^{\circ} \mathrm{C}$ to $280{ }^{\circ} \mathrm{C}$, adjacent machine for high pressure steam extraction steam source, a smoke generally comes from the high pressure cylinder body, three smoke generally comes from the middle pressure cylinder body, restricted by the existing pipe diameter and pipe flow, the extraction steam quantity is limited, So it's out of the question. And two pumping (generally from high pressure cylinder exhaust steam) or cold again, pumping steam volume is large and sufficient, so choose this way pumping steam source. Combined with the direction and space of the onsite pipeline of secondary pumping or cold reheating and the convenience of transformation, the available steam extraction positions generally include secondary pumping, cold reheating, cold reheating to auxiliary steam [4] and cold reheating to small machine. For the ultrasupercritical secondary reheat unit, the third pumping is the high exhaust, so the selected extraction position is the third pumping. The \#2 high heater of the machine is matched with the steam source of the temporary machine extraction steam. The \#2 high heater has the strongest heat exchange capacity and the largest water side temperature rise in the high heater.

Taking a unit as an example, the adjacent unit heating system is shown in Figure 1. The steam contact mother pipe is set between the second section of the extraction pipe of the two units, and the steam is supplied to the \#2 high of the two units respectively. An electric gate valve and a pneumatic regulating valve are set between the mother pipe and the \#2 high steam adding pipe, respectively, to adjust the high amount of steam added into the starting unit \#2, so as to control the temperature rise rate and temperature of the water supply. If the hydrophobic artefact flows through the normal hydrophobic pipe of \#2 high heater to \#3 high heater, the input of \#3 high heater will be affected. Part of heat will be lost if it is discharged to the condenser through the \#2 high-add accident drain pipe. Therefore, a \#2 high-add drain pipe to the deaerator is added in front of the $\# 2$ highadd normal drain electric door, which is connected to the standby interface of the deaerator to recover the \#2 highadd drain [5] during the heating of the neighboring machine.

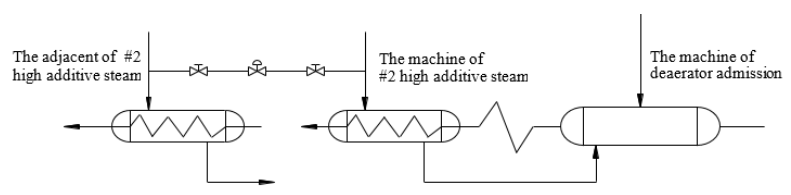

Figure 1. Heating system diagram of adjacent machine

\subsection{Heating in and out of adjacent machine}

Adjacent machine normal operation, the machine starts up, using auxiliary steam to deaerator heating water to the boiler water after the required temperature, feed water pump to start cold rinse boiler, in the process of driving the auxiliary steam to adjust the door deaerator admission, slowly lift deaerator water temperature, and adjacent machine two smoke to the machine \# 2 high pipeline warming pipe, preheating. After the cold flushing, slowly open the adjacent machine to heat the steam supply regulating valve, and increase the volume of steam added by \#2. When the water temperature at the outlet of \#2 high heating reaches the temperature required for hot flushing, hot flushing is performed on the boiler. After the hot state flushing is completed, the boiler is ignited and started. The boiler enters the stage of pressure boost and temperature rise, and continues to slowly open the adjacent unit to heat the steam supply regulating valve to improve the water supply temperature. During the process of pressure boost and temperature rise, the change rate of high water supply temperature is strictly controlled to not exceed the prescribed limit. After the turbine is turned on or the generator is juxtaposed, input \#3 high heater and \#1 high heater in turn. With the increase of unit load, gradually close the heating inlet adjustment door of \#2 high heater, switch the steam source of \#2 high heater from the adjacent machine to the machine, and switch the hydrophobic self-flow operation mode of \#2 hydrophobic self-flow to exit the heating system of the adjacent machine.

\subsection{Precautions for heating operation of adjacent machine}

1) The pipes of adjacent heating and connecting two machines are generally longer, and the temperature and pressure of adjacent heating and steam supply are higher, so it is necessary to carry out adequate heating pipe and drainage before putting into adjacent heating to prevent the impact of soda water and the severe vibration of the pipe and damage the equipment. When heating pipe of adjacent machine, it is necessary to strengthen the monitoring of wall temperature change of adjacent machine heating pipe and check the vibration of pipe locally.

2) In order to prevent the steam turbine from entering water, it should be confirmed that the steam trap pipe and crisis trap pipe of \#2 high feeder can be put into operation normally, and the protection of \#2 high feeder water level can also be put into operation normally before the adjacent unit is put into operation. When steam heating of \#2 high heating machine is put into operation, the temperature rise rate of heater should be controlled, and the feed water flow should be kept stable to prevent \#2 high heating leakage caused by the excess of \#2 high heating temperature rise. At the same time, attention should also be paid to the \#2 high water level, control the difference between the \#2 high water level and the lower end of the \#2 high water level, to prevent the steam liquid two-phase flow in the hydrophobic cooling section from causing the vibration of the hydrophobic pipeline or the \#2 high water level leakage. 
3) During the heating of the adjacent machine, the steam is taken from the cold reheater of the adjacent machine, which leads to the reduction of the steam intake of the reheater of the adjacent machine, which may lead to the overtemperature of the wall of the reheater [6], and may also lead to the change of the axial thrust of the adjacent machine. Therefore, the wall temperature of the reheater of the adjacent machine should be monitored during the heating of the adjacent machine, the inlet steam regulating valve of the adjacent machine should be opened slowly, and the combustion of the adjacent machine can be properly adjusted in advance. The axial displacement and thrust bearing temperature of the adjacent machine should also be monitored. At the same time, attention should also be paid to monitor the pressure of the first and second monitoring sections of the neighboring machine to prevent overload of the last stage blade of the highpressure cylinder of the neighboring machine.

4) After the heating of the adjacent machine is put into operation, attention should be paid to the temperature difference between the upper and lower cylinders of the high-pressure cylinder and the turning speed of the machine, so as to prevent the heating steam of the adjacent machine from flowing back into the high-pressure cylinder of the machine due to the loose check valve and electric valve of the cold reheating pipe.

5) When the adjacent machine is heated out, the feed water temperature should be well controlled to prevent the boiler feed water temperature change rate from increasing due to the rapid drop of the feed water temperature, resulting in the increase of the stress on the supertemperature heating surface of the pipe wall. After the heating and exit of the adjacent machine, the steam supply regulating valve and gate valve of the adjacent machine should be strictly closed to prevent the steam leakage between the units caused by the loose valve.

\section{Benefit analysis of adopting adjacent heating technology}

\subsection{Economic benefits}

For the machine, the cost of steam heating water supply is far lower than the cost of fuel oil or coal heating water supply, saving the fuel oil and coal cost in the start-up stage, and in the process of steam heating water supply, the furnace side of the three fans and the coal mill did not start, saving the auxiliary boiler power. In the hot state flushing stage of boiler, the effect of state flushing is strengthened and the time of state flushing is shortened. In the stage of boiler temperature rise and pressure boost, the temperature of boiler feed water is further increased by the adjacent machine heating, and the rate of boiler temperature rise and pressure boost is accelerated.

For the neighboring machine, because the heating steam from the neighboring machine has been sent to the exhaust steam, equivalent to the combined heat and power supply, according to the current calculation method of heat and power unit economic indicators, the thermal efficiency of this part of the steam is $100 \%$, improve the economy of the neighboring machine.

\subsection{Security benefits}

After adopting the steam heating technology of adjacent machine, the boiler is in the favorable state of "hot air, hot furnace and hot environment" when ignition and starting, and the boiler starts from the cold state to the hot state, which improves the ignition condition and stable combustion condition of the boiler and improves the safety of boiler starting. As a result of raising the furnace temperature, improve the initial combustion environment of boiler ignition, improve the combustion efficiency and burnout rate of pulverized coal, fuel oil, avoid incomplete combustion of oil smoke caused by boiler tail flue equipment, electric dust removal equipment harm. It also improves the exhaust temperature at the start-up stage, greatly reduces the probability of condensation and ash blocking of SCR denitration device and air preheater, and reduces the adhesion of unburned ash.

After heating technology adopted adjacent machine, the boot process, the boiler water wall temperature rise rate is more gentle, avoid the superheater and reheater shall be under dry and then steam into after quenching, which can effectively prevent scale caused by dramatic change wall temperature fall off, also reduced the solids flow part of steam turbine dynamic and static blade erosion damage, The safety and reliability of unit operation are improved.

\subsection{Environmental benefits}

In the stage of boiler hot flushing and the stage of temperature rise and pressure boost, it is put into the heating system of adjacent machine, which reduces pollutant discharge and can obtain good environmental protection benefit. When the boiler hot flushing is over and the boiler ignition is started, the SCR denitration device can be put into operation normally, ensuring that the NOx in the exhaust does not exceed the standard. The electric dust removal device can also be put in early to ensure that the dust in the smoke exhaust does not exceed the standard. At the same time, due to the good dust removal effect, prevent the flue gas of unburned oil, coal powder and dust from entering the desulfurization system to affect the activity of absorbent, ensure the desulfurization efficiency, reduce the content of sulfur dioxide in the flue gas.

\section{Other types of adjacent heating}

As mentioned above, adjacent steam is used to heat water supply during the boiler start-up stage, which is a common technical scheme. There are also some other adjacent steam heating schemes in the actual application of power plants.

\subsection{The steam of adjacent machine realizes the start of medium pressure cylinder}

For the unit with no high pressure bypass and low pressure low side bypass and only one large bypass, the steam engine can only use the high pressure cylinder starting mode. Single start-up mode, and after the unit is flushed, the high discharge temperature is low, and the cold reheat and reheat pipeline is long, making the reheat temperature 
into the medium pressure cylinder low, easy to cause the vibration of the bearings at both ends of the medium pressure cylinder, resulting in prolonged startup time, increasing the start-up cost.

This problem can be effectively avoided by using adjacent steam to start the medium pressure cylinder [10]. The cold and reheated steam from the adjacent machine is introduced into the cold and reheated pipe of the machine, and after pre-heating the high pressure cylinder of the machine, it enters the reheater of the machine. After the boiler is ignited, it enters the medium pressure cylinder of the machine through the hot reheated pipe to start the medium pressure cylinder of the machine.

\subsection{Steam trial operation of adjacent machine in commissioning stage}

During commissioning of a new unit, a series of test items should be carried out when it is running at no load and low load. This requires boiler ignition to maintain low load combustion, and these test projects are difficult to succeed at a time, with the exposure and elimination of defects, the unit repeatedly start and stop, which brings high energy consumption, pollution problems. In order to solve this problem, some units adopt the adjacent steam scheme during commissioning. The specific method is to direct the main steam of the adjacent cooling regenerator or the high side of the adjacent cooling regenerator after temperature reduction and pressure reduction to the cooling regenerator pipe of the machine, and then through the reheater and heat regenerator pipe of the machine to the main door of the machine to complete the turbine turning and carry out corresponding test projects [11].

\section{Conclusion}

Thermal power unit adopts adjacent heating technology, which improves the ignition conditions and stable combustion conditions of the boiler, and enhances the start-up safety of the boiler. Both saving the cost of the fuel oil, coal, electricity, strengthened the flushing efficiency, shorten the flush time, improve the economic benefit of the adjacent machine, and prevent the oxide skin peeling caused by dramatic change wall temperature, also can guarantee the safe operation of desulphurization and denitration, dust removal equipment, reduce the pollutant emissions, therefore has wide application prospect.

\section{References}

1. CAO Yan. Research on steam Heating start-up technology of large ultra (ultra) critical direct current boiler. Shanghai University of Electric Power, 2014.

2. Xiao Feng. Research and application of economic start-up of $1000 \mathrm{MW}$ unit. Guangdong electric power, 2011, 24(02): 37-40+96.

3. Cui Min, Zhao Hongwei. Design of adjacent Steam Heating system for $2 \times 1000 \mathrm{MW}$ Unit Expansion Project of Anqing Power Plant Phase II. Energy conservation, 2015, (12): 34 to 37.
4. Li Yanmin. Application of adjacent heating technology for $1000 \mathrm{MW}$ ultra-supercritical unit. Electric power safety measurement, 2016, 18(01):1012.

5. Liu Linqiang. Application of Adjacent Steam Heating for 600MW Unit. Chinese Energy Society. China Energy Society: Beijing Zhongneng Lianchuang Information Consulting Co., LTD, 2015:6.

6. Niu Liquan. Application of adjacent heating system in supercritical unit. Huadian technology, 2015, 37(08): 56-58+78.

7. Xu Jiaye, Zhu Xiaolei, Li Jianning, et al. Application and analysis of full load denitrification technology. Journal of power engineering, 2020, 40(07): 580$585+604$.

8. Xia Jing. Adjacent heating startup technology of 600 MW supercritical unit. Electric power safety technology, 2014, 16(07): 15-16.

9. Jia Lifeng. Application of adjacent Heating technology in 1000 MW ultra-supercritical unit. Huadian technology, 2019, 41(04): 66-67+73.

10. Liu Bin, Shao Changnuan. Application of adjacent Heating start-up technology in 1000 MW ultrasupercritical unit. Huadian technology, 2019, 41(01): 74-76.

11. Bu Junfeng. Trial operation scheme of supercritical unit using adjacent steam. Shandong electric power technology, 2020, 47(03): 70-73. 